\title{
THE ELECTROCARDIOGRAM IN SENILE ARTERIAL DISEASE
}

\author{
By Douglas Robertson, M.A., D.M.(Oxon.), M.R.C.P.(Lond.) \\ Consulting Physician and Cardiologist in the S.E. and S.W. Metropolitan Regions
}

There is no electrocardiogram peculiarly associated with senile arterial disease; nevertheless it is not infrequently that an abnormal electrocardiogram is found in older patients who present primarily with symptoms suggesting peripheral arterial disease, because in them it is quite usual for the coronary arteries to be involved as well. Effectively, therefore, a proper study of the electrocardiogram in such patients will include all conditions caused by arteriosclerotic coronary artery disease, even major coronary occlusion and cardiac infarction. Further, since these subjects are often hypertensive, such a study would include the whole of arteriosclerotic hypertensive heart disease also. These matters are beyond the size or scope of this article, and for the numerous electrocardiographic appearances associated with such primarily cardiac conditions the reader should consult current textbooks of electrocardiography.

I will, then, confine myself to some electrocardiograms found in senile patients who have presented, not as cardiacs, but with generalized senile arterial disease-very usually obliterative arteritis affecting the lower limbs. And, with one exception (Fig. 9b), all the illustrations were recorded in one year (1953) - in two hospital clinics, and private practice-so that it will be appreciated that such, more or less incidental, electrocardiographic findings are very common. These illustrations serve pretty well for a brief review of a large subject. Also for reasons of space, the illustrative electrocardiograms are shown (in most cases) in the three bipolar limb leads (Einthoven leads) only, without accompanying chest leads. Usually these three leads alone serve quite adequately enough to illustrate the essential features described.

Fig. I shows what might be called a ' normal' electrocardiogram in an old lady (73); nevertheless I think it will be agreed that such an electrocardiogram in a young subject would be unusual. There is slight relative widening of QRS in Leads I and 2 (compared with the height of $\mathrm{R}$ );

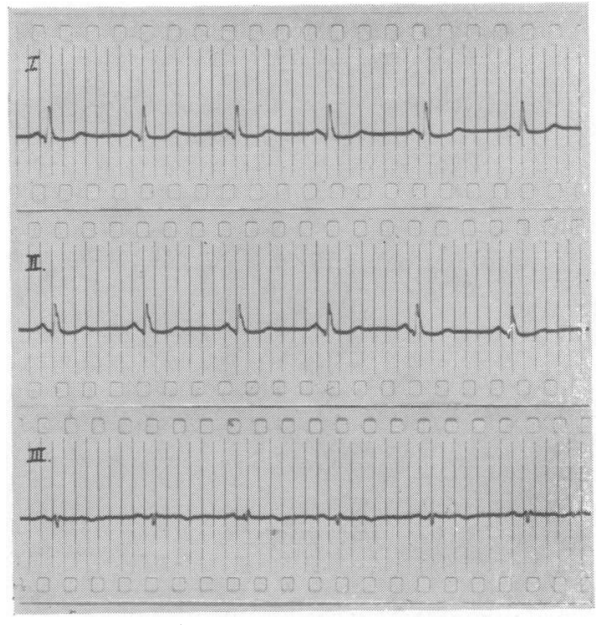

FIG. I.-A ' normal' electrocardiogram at age 73 (time markings 0.1 sec. in every case).

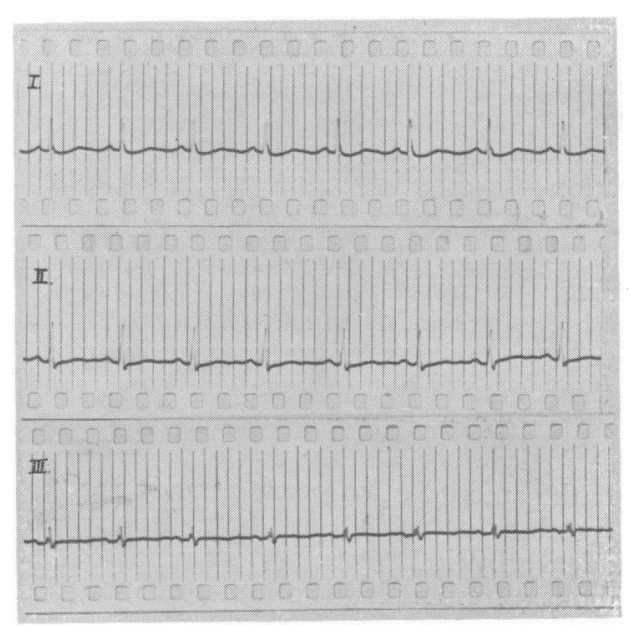

Fig. 2.-Low voltage $T$ waves (age 76 ). 


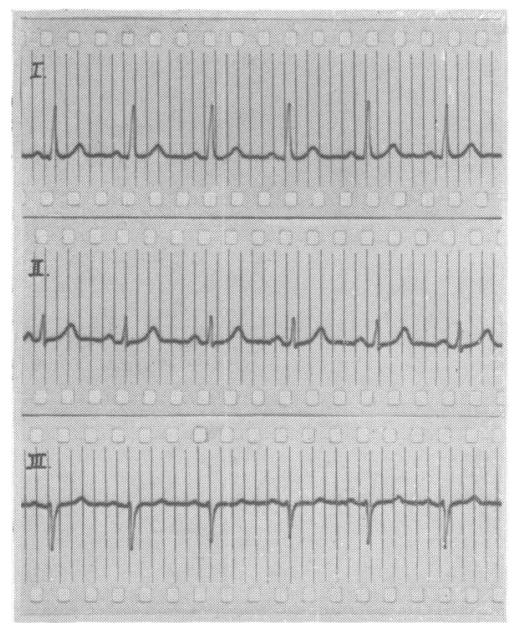

Fig. 3.-Simple left axis deviation (age 62).

there is slight depression of ST in these two leads; the voltage of the $T$ waves is not such as would be normal in a young subject. Yet all the time intervals and wave voltages fall within accepted normal limits, nor is there even any axis deviation. It is the general consolidated slightly abnormal appearances which make it reasonably sure that this curve is from an old subject, even though there was no significant heart disease in this case. Low voltage of the $T$ waves is also a feature of the electrocardiogram of Fig. 2 (a 76-year-old woman); this is not unusual in old age, and is not necessarily abnormal. In a younger patient it might well suggest myxoedema, or myocarditis.

Fig. 3 (a 67-year-old male) shows a deep $\mathrm{S}$ in Lead 3-left axis deviation. This is a common finding in these elderly subjects; it is caused by anticlockwise (viewed from the apex of the heart, i.e. from 'below') twisting of the heart along its own long axis, because of the elongation of the aorta, caused by atheroma and subsequent calcification-so-called ' uncoiling' of the aorta. In this case there was some hypertension, but no significant heart disease. The same thing can, of course, be produced by left ventricular hypertrophy, whatever its cause; but in that case there may be preterminal inversion of $T$ in Lead $I$, due to thickening of the wall of the left ventricle; then the degree of left axis deviation is definitely pathological.

If the amount of coronary arteritis is so great as to produce actual closure of a branch, whether suddenly by intravascular thrombosis or arterial embolism from a plaque of atheroma, or (possibly) more gradually, from atheromatous narrowing, then actual infarction of the wall of the ventricle will occur. The patient is then a primary cardiac

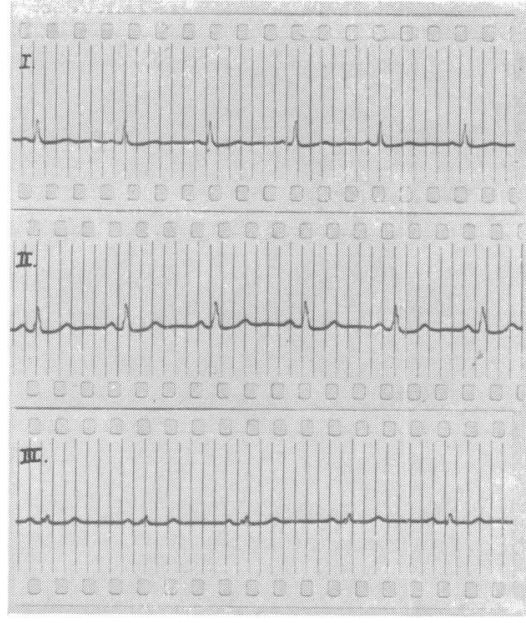

FIG. 4.-An electrocardiogram showing $T_{1}$ voltage less than $\mathrm{T}_{3}$ (age 67).

case, and the electrocardiographic appearances are음 those of cardiac infarction-legion in number, according to the site and size of the infarct. That large subject cannot be treated in this article. But if there is a diffuse coronary arteritis the blood supply to the myocardium may be quite adequa\& $\vec{c}$ for the ordinary life of the patient, only becoming inadequate when increased physical exertion, 훙무 emotion, demands an increased cardiac output, which in turn demands increased blood supply to the myocardium which the narrowed coronary vessels are unable to deliver. There then develop, $\frac{\mathbb{Q}}{\mathbb{Q}}$ together with the angina, the electrocardiographic appearances of coronary insufficiency. When this is considerable there is depression of the ST segment, which is especially evident in Lead 2 and in chest leads from the apical region (positions 4 and 5). But, in addition, there is a change of $\frac{0}{3}$ shape of the ST-T section, which is particularly evident if attention is directed to the angle between 3 the ST segment and the upgoing limb of the T wave; this angle becomes sharper, and more 3 rectangular, than normal. Also, the ST segment o becomes more isoelectric, or even downgoing and more linear. It is these features, more than the actual depression of ST, which connote ischaemia of the myocardium. Figs. 5 and 6 are $\stackrel{N}{\sigma}$ good illustrations, from a patient (age 77) who N had considerable endarteritis of the legs, and a N mild effort angina. Here there is no significant $\omega$ depression of ST after exercise (which produced some angina), though the ST-T angulation is plainly evident in Leads 2 and $\mathrm{CR}_{4} \cdot{ }^{*}$ This angula- $\stackrel{\mathscr{\Phi}}{+}$

*Lead $\mathrm{CR}_{4}$ is the lead which shows ischaemic change most easily. For this purpose it is superior to (unipolar) lead $V_{4}$. 


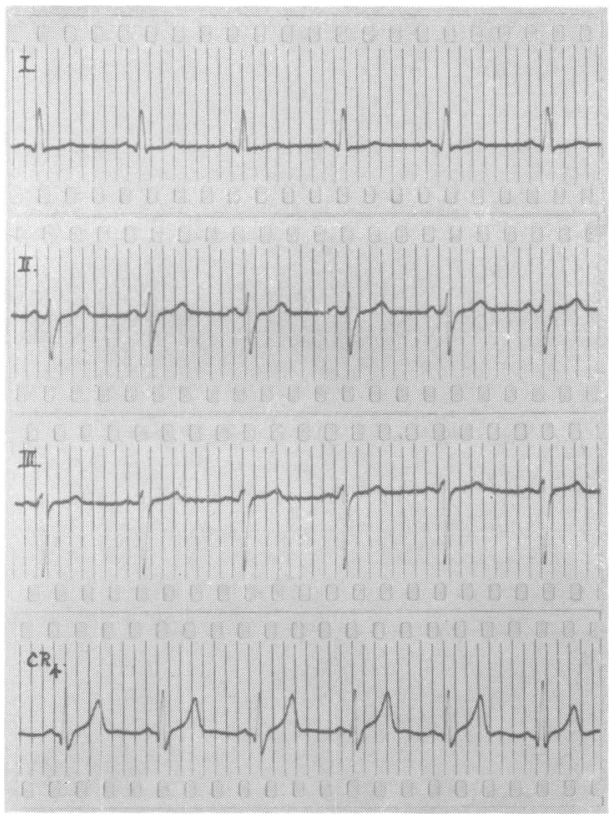

FIg. 5.-Simple left axis deviation at rest. Normal enough at his age (77).

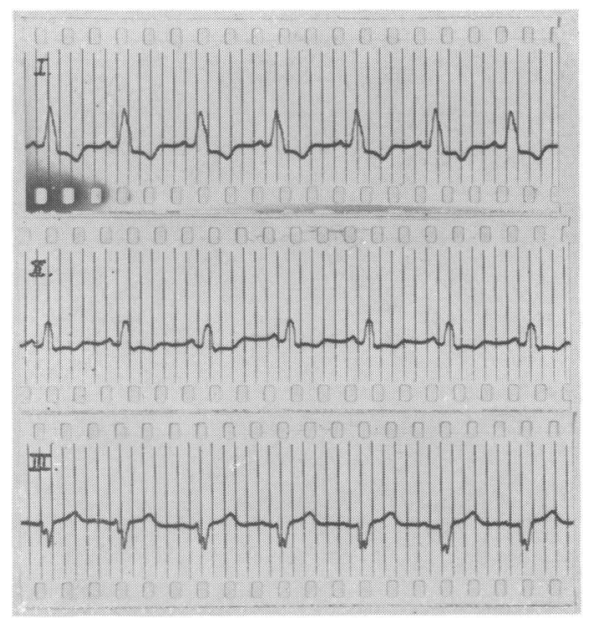

Fig. 7.-Left bundle-branch block (age 7I).

tion of ST-T is not usually stressed in textbooks on electrocardiography, and should receive more attention than has so far been directed to it.

Fig. 4 is from a patient (age 67 ) who was greatly incapacitated by his lower limb arteritis. Superficially it is not obviously abnormal ; but it has one feature which is often indicative of diffuse coronary sclerosis, that is that the voltage of $T_{1}$ is less than

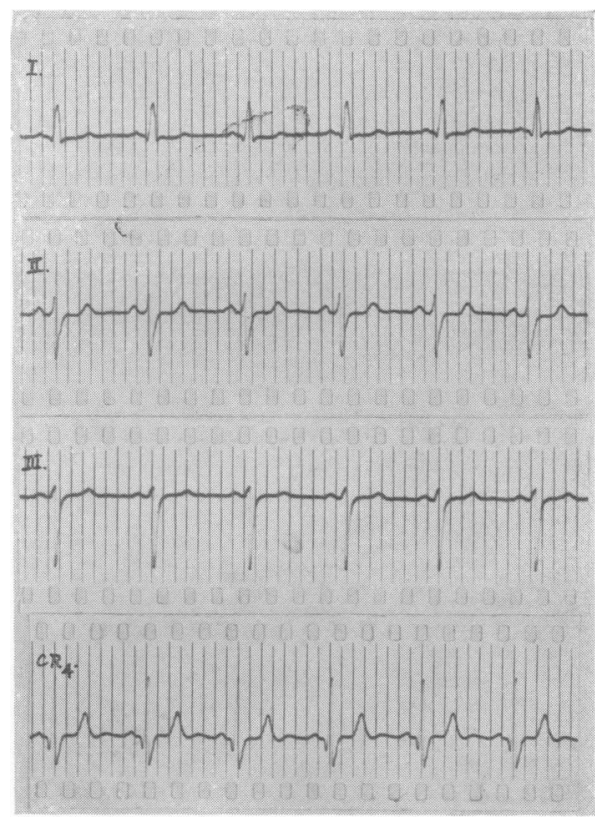

FIG. 6.-The same after exercise. Ischaemic changessee text.

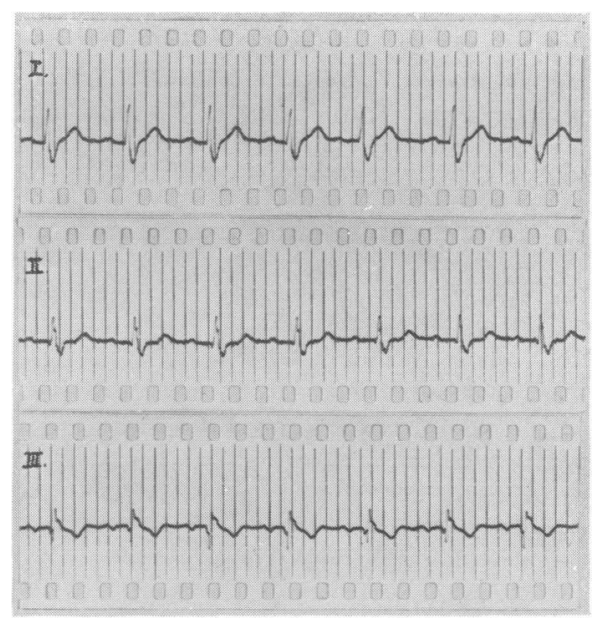

FIG. 8.-Right bundle-branch block (age 63).

that of $\mathrm{T}_{3}$. This is evident in Fig. 5 also, though there it is less obvious. This finding is present in some cases of lateral infarction, but then there is clear evidence of the infarct in the outer chest leads. In this case (Fig. 4) there was no history suggestive of cardiac infarction.

The aging myocardium is also liable to cause disorders of rhythm, which may happen without 
FIG. 9a.-Complete heart block (there is also left axis deviation).

FIG. 9b.-Nodal rhythm; regular ventricular extrasystole; Wenckebach periodicity of the retrograde $P$ wave-see text.

FIG. 9c.-Decreased voltage of the $T$ wave of the sinus beat immediately following a ventricular extrasystole.

FIg. 9d.-Actual inversion of a similar $\mathrm{T}$ wave.

any symptoms and which may therefore be a merely incidental finding in the physical examination of the patient. Of these by far the commonest is auricular fibrillation, and many people can have been fibrillating for years without any, or no more than slight, disability. Auricular flutter and paroxysmal tachycardia can also occur, though unpleasant cardiac symptoms are more usual in these patients, so that they will present primarily as cardiacs. It is generally accepted that the abnormal irritable focus in these disorders is usually caused by focal ischaemia due to localized coronary disease-when they occur in older subjects.

If the ischaemia selectively affects the conducting system of the heart (Bundle of His, its branches, or the Purkinje fibres), various electrocardiographic abnormalities may become evident, as well as disorders of rhythm. Bundle-branch block (Figs. 7 and 8) or (so-called) arborization block may occur, and is quite commonly a merely incidental finding; this was the case in both these patients. Arborization block, evidenced by a prolonged, low voltage, and splintered QRS, bears a more sinister implication than frank right or left bundle-branch block-it usually signifies widespread myocardial degeneration. The electrocardiogram of Fig. 9a shows Complete Heart-block (and

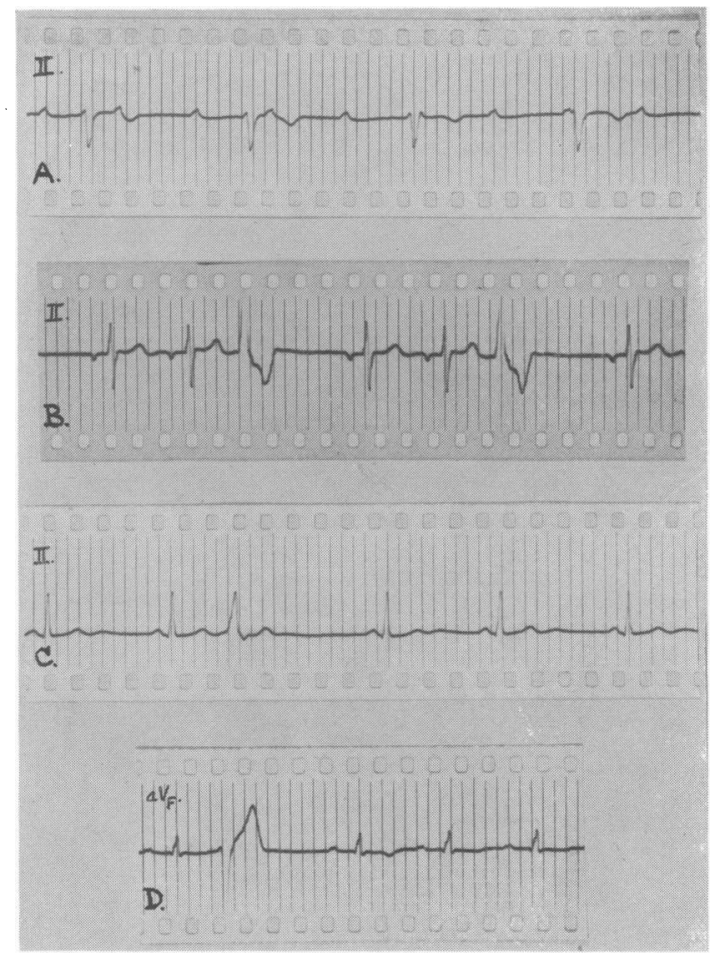

considerable left axis deviation); this patient (age 6r) presented as a surgical case, having sustained burns during her first (presumably) Stokes-Adams attack. Fig. gb shows an uncommon disorder of rhythm, found in a 68-year-old with obliterative arteritis of the legs. Here there is high A-V nodal rhythm, with regular ventricular extrasystole occurring after every second 'regular' beat. There is also Wenckebach periodicity of the retrograde conducted auricular beat, as evidenced by the increasing length of the ' $P-R$ ' interval; this is caused by the increasing fatigue of the bundle of $\mathrm{His}$, and its eventual failure to conduct the impulse to the ventricle, giving way to the ectopic ventricular focus.

Extrasystoles, from various foci-most usually ventricular or auricular-are a very common inci- $\rightarrow$ dental finding at all ages, but perhaps especially in old age. The physician's problem is to assess N their pathological significance. When they occur in young subjects they are usually innocent, and there is no organic heart disease. This may be the case in the older patient; but it can be that they signify early myocardial degeneration or coronary sclerosis, so that some further assessment of their $\mathbb{D}$ significance is important. Generally speaking, ? homomorphic (all of the same shape, and therefore all from the same focus) extrasystoles are innocent, 
while pleomorphic (variform-originating from many foci) extrasystoles are significant. Nevertheless this is not always so and homomorphic extrasystoles can occur where there is myocardial disease.

Extrasystoles which are evoked by exercise usually signify organic heart disease, whereas innocent extrasystoles are most often abolished by exercise. Where frequent auricular extrasystoles are observed they may presage the early onset of auricular fibrillation.

A diminution in the height of the $\mathrm{T}$ wave of the sinus beat immediately following the extrasystole, or even its frank inversion, is sometimes encountered. Figures $9 \mathrm{c}$ and $\mathrm{d}$ illustrate these two points. When this is found there is more likely to be a diseased myocardium, and Mann and Burchell, working at the Mayo Clinic, say that this is so in 93 per cent. of cases-in a series of 46 patients showing inversion of the post-extrasystolic $T$ waves.

It is difficult to estimate what proportion of elderly patients with peripheral arterial disease have abnormal electrocardiograms, without having any cardiac symptom, but it must be high, and probably very high. It is significant that Levitt states ' approximately 25 per cent. of apparently healthy men and women over the age of 70 probably have considerable myocardial damage, for he found distinct electrocardiographic abnormalities in that number who had no evidence of $\bar{\sigma}$ any heart disease, and none of his cases are reported as having peripheral arterial disease.

\section{BIBLIOGRAPHY}

DRESSLER, W and ROESLER, H (1948) 'The diagnostic value of the pattern $T_{1}$ lower than $T_{3}\left(T_{1}<T_{3}\right)$ compared with the information yielded by multiple chests leads in with the information yielded by multiple chests leads in $\vec{A}$

LEVINE, H. D., LOWN, B., and STREEPER, R. B. (1952), $\omega$ "The clinical significance of postextrasystolic T-wave changes,' Circ. 6, 538 .

LEVITT, G. (1939), 'The electrocardiogram in the aged,'Amer. Heart $\mathcal{F} ., 18,692$.

MANN, R. H., and BURCHELL, H. B. (I954), 'The signifi- $\omega$ cance of $T$-wave inversion in sinus beats following ventricular :extrasystoles,'. Ibid., 47, 504.

SCHERF, D. (1944), "Alterations in the form of the $T$ waves $O$ with changes in heart rate,' Ibid., 28, 332.

UNGERLEIDER, H. E., and GUBNER, R. (r947), "The $Q_{3} \vec{N}$ and $O S$, deflections in the electrocardiogram: criteria and significance,' Ibid., 33, 807 .

WILLIUS, F. A. (193I), 'The heart in old age', Amer. F. Med. Sci., 182, 1 .

\section{OBSTETRICS \& GYNAECOLOGY}

(Postgraduate Medical Journal, July, 1954)

Price : 3s. 8d., post free

\section{INTRODUCTORY}

Charles D. Read, F.R.C.S., F.R.C.O.G.

\section{RESPIRATORY HAZARDS IN THE} PREMATURE INFANT

Albert E. Claireaux, M.D., M.R.C.P.

\section{POSTMATURITY}

S. G. Clayton, M.D., M.S., F.R.C.O.G.

THE RELATIVE MERITS OF THE VARIOUS BIOLOGICAL TESTS FOR PREGNANCY

H. P. Ferreira, M.D.

\section{PELVIC THROMBOSIS}

J. Stallworthy, F.R.C.S., F.R.C.O.G.

THE EARLY DIAGNOSIS OF GENITAL CANCER BY CYTOLOGY

Erica Waechtel, M.D.

THE MENOPAUSE

G. I. M. Swyer, D.M., M.R.C.P.

THE PLACE OF ULTRA-RADICAL SURGERY IN ADVANCED MALIGNANT DISEASE IN THE PELVIS

J. B. Blaikley, F.R.C.S., F.R.C.O.G.

Published by

\section{THE FELLOWSHIP OF POSTGRADUATE MEDICINE}

